International Journal of Medical Sciences

ISSN 1449-1907 www.medsci.org 2008 5(4):181-188

Research Paper

(C) Ivyspring International Publisher. All rights reserved

\title{
Receipt of Standard Breast Cancer Treatment by Airican American and White Women
}

\author{
Julie Worthington ${ }^{1}$, John W. Waterbor ${ }^{2}$, Ellen Funkhouser ${ }^{3}$, Carla Falkson ${ }^{4}$, Stacey Cofield5, and Mona \\ Fouad $^{3}$
}

1. Division of Gastroenterology, Case Western Reserve University, Cleveland, OH, USA.

2. Department of Epidemiology, University of Alabama at Birmingham, Birmingham, AL, USA.

3. Division of Preventive Medicine, University of Alabama at Birmingham, Birmingham, AL, USA.

4. Division of Hematology/Oncology, University of Alabama at Birmingham, Birmingham, AL, USA.

5. Department of Biostatistics, University of Alabama at Birmingham, Birmingham, AL, USA.

Correspondence to: Julie Worthington, $\mathrm{PhD}$, Division of Gastroenterology, Case Western Reserve University, Biomedical Research Building Room 423, 10900 Euclid Avenue, Cleveland, OH 44106-4952. Phone (216) 368-6937; Fax (216) 368-1674; E-mail Julie.Worthington@case.edu

Received: 2008.05.19; Accepted: 2008.07.06; Published: 2008.07.07

Objectives: Breast cancer mortality is higher among African Americans than for Whites, though their breast cancer incidence is lower. This study examines whether this disparity may be due to differential receipt of treatment defined as "standard of care" or "addition to standard of care" by the National Comprehensive Cancer Network (NCCN).

Design: Incident, female breast cancer cases, 2,203 African American and 7,518 White, diagnosed during 1996-2002 were identified from the Alabama Statewide Cancer Registry. Breast cancer treatment was characterized as whether or not a woman received standard of care as defined by the NCCN. For cases characterized as receiving standard of care, addition to standard of care was also evaluated, defined as receiving at least one additional treatment modality according to NCCN guidelines. Logistic models were used to evaluate racial differences in standard and addition to standard of care and to adjust for age, stage at diagnosis, year of diagnosis and area of residence.

Results: No racial differences were found for standard (Prevalence Ratio (PR)=1.00) or for addition to standard of care $(\mathrm{PR}=1.00)$ after adjustment for confounders. When the adjusted models were examined separately by age, stage, and area of residence, overall no racial differences were found.

Conclusion: No racial differences in standard of care and addition to standard of care for breast cancer treatment were found. Therefore, both African Americans and Whites received comparable treatment according to NCCN guidelines.

Key words: Breast Neoplasms, Therapeutics, standard of care, racial disparities, cancer registry

\section{INTRODUCTION}

Breast cancer is the most common cancer among women (about one of every 3 cancers diagnosed) in the United States, excluding cancers of the skin [1]. In 2008 in the United States, 182,460 new female breast cancer cases are estimated to occur and 40,480 are expected to die from this cause [2]. Even though mortality rates have been declining for both races, the decline for African Americans is half that of Whites [3]. The breast cancer mortality rate is higher among African Americans than Whites, though their breast cancer incidence rate is lower [3].
Excessive cancer mortality in minority populations, especially African Americans, has long been recognized and has been shown to be partly due to stage distribution at diagnosis; however, the reasons for these racial disparities are not completely understood $[1,4]$. Several studies have examined whether variation in treatment, surgery and/or adjunct therapy explains this racial disparity in mortality [5-18, 19]. Few studies with adequate sample sizes have examined racial differences between African Americans and Whites with regard to receipt of recommended breast cancer treatment $[10,12,13,16]$. Results have been mixed with two studies finding a racial difference in 
treatment $[10,16]$ and two finding no difference after adjustment for varying predictors $[12,13]$. This study examines whether part of this racial disparity may be due to differences in receipt of National Comprehensive Cancer Network (NCCN) recommended treatment in a population with a large proportion of African Americans.

\section{METHODS}

\section{Study Population}

Data on all first primary incident breast cancer cases were identified from the Alabama Statewide Cancer Registry (ASCR) founded in 1996. Incident, female cases, 2,203 African American and 7,518 White, who were 19-65 years of age and living in Alabama when diagnosed over the 7-year period 1996-2002, were eligible for inclusion in this study. Because stage at diagnosis was necessary to assess standard of care with the NCCN recommendations (see below: Outcome Measures), patients with unknown stage were excluded from the standard of care assessment as well as stage 0 cases so only invasive cancer was examined.

\section{Outcome Measures}

Standard of care was defined as receiving breast cancer treatment as recommended by the NCCN guidelines for her specific diagnosis year and stage at diagnosis. For example, if the NCCN recommended only chemotherapy, the patient received standard of care if the patient only received chemotherapy. Among those receiving standard of care, addition to standard of care was defined as receipt of the NCCN recommended breast cancer treatment plus at least one additional treatment modality. Addition to standard of care was considered receiving additional treatment than recommended. For example, if the NCCN recommended only chemotherapy and the patient received chemotherapy and radiation therapy, the patient received the additional treatment of radiation therapy and would be defined as receiving addition to standard of care. Because no treatment for stage IV was considered to be appropriate according to the NCCN recommendations, all stage IV patients were considered to have received standard of care.

To determine whether or not standard of care/addition to standard of care was received, computer algorithms were developed to compare the actual treatment to recommended treatment for specific year of diagnosis and stage according to lymph node status, tumor size, age, and estrogen receptor status for each breast cancer case. For example, if a breast cancer case diagnosed in 1997 with stage II, aged 55 years, had a tumor size $>50 \mathrm{~mm}$, and was ER+, the treatment this patient should have received included mastec- tomy or lumpectomy, radiation therapy, and hormone therapy according to NCCN recommendations. If the patient received all of these treatments, the patient received standard of care. If the patient also received chemotherapy which was not recommended, then the patient received addition to standard care. The principal investigator and two assistants composed and checked the algorithms as a means of quality control.

NCCN recommendations were revised in 1996, 1997, 1999 and 2000 though changes were minimal. NCCN does not allow publication of detailed guidelines from previous years, however a summary of the recommendations are as follows: In most years, mastectomy without radiation or lumpectomy with radiation was recommended for stages I and II. Radiation with mastectomy was typically recommended only for cases having large tumors. Chemotherapy was typically recommended for women younger than 50 years old or those in stage III, and hormone therapy was recommended for women whose estrogen receptor status was positive and whose age was 50 years or older.

\section{Study Measures}

Information collected from ASCR included identification of the incident breast cancer cases, demographics, estrogen receptor status, stage at diagnosis, year of diagnosis, lymph node status, tumor size, type of breast cancer treatment received (surgery, radiation, chemotherapy, and hormone therapy), and county of residence. The NCCN guidelines are based on clinical staging, thus the American Joint Committee on Cancer (AJCC) clinical staging was used when available. When clinical stage was missing (38\% of cases), the AJCC pathological stage was used allowing the percent of missing to be only $17.7 \%$ of cases $(\mathrm{N}=1721)$. Using the United States Census definitions, Metropolitan Statistical Area (MSA) counties were considered urban areas while non-MSA counties were considered rural areas.

\section{Statistics}

Chi-square tests were used to evaluate differences in characteristics between African Americans and Whites. A binary logit model was used to evaluate the relationship of standard of care and race (African American versus White), computing the crude and adjusted prevalence ratios (PRs) and the corresponding 95\% confidence intervals [20]. PRs were adjusted for age, stage of diagnosis, year of diagnosis, and area of residence (urban vs. rural). Because estrogen receptor status was highly correlated to hormone therapy, estrogen receptor status was not included in the multivariate models. Separate models were computed by area of residence, stage at diagnosis, and age. 
P-values $<0.05$ were considered to be statistically significant. Analyses were performed using SAS statistical software version 9.0 (SAS, Cary, NC).

\section{RESULTS}

Characteristics of incident African American and White female breast cancer cases from 1996-2002 are shown in Table 1. African Americans were younger at the time of diagnosis, more likely to be estrogen receptor negative and more likely to be diagnosed at a later stage compared to Whites (all $\mathrm{p}$ values <0.001).
African Americans were more likely to undergo mastectomy and chemotherapy compared to Whites (both $\mathrm{p}<0.001)$, while Whites were more likely to undergo lumpectomy $(\mathrm{p}<0.001)$ and radiation $(\mathrm{p}=0.06)$. When each breast cancer treatment (surgery, radiation, chemotherapy and hormone therapy among estrogen receptor positive) was evaluated in a binary logistic model, no racial differences were found when adjusted for age at diagnosis, stage at diagnosis, year of diagnosis and area of residence (data not shown).

Table 1. Characteristics of incident breast cancer cases in Alabama, 1996-2002

\begin{tabular}{|c|c|c|c|c|c|c|c|}
\hline \multirow{4}{*}{ Age (years) } & \multirow{2}{*}{\multicolumn{2}{|c|}{$\begin{array}{c}\text { All } \\
\mathbf{N}^{*}=9721\end{array}$}} & \multirow{2}{*}{\multicolumn{2}{|c|}{$\begin{array}{c}\text { White } \\
\mathbf{N}^{*}=7518\end{array}$}} & \multirow{2}{*}{\multicolumn{2}{|c|}{$\begin{array}{l}\text { African-American } \\
\qquad N^{*}=2203\end{array}$}} & \multirow[b]{3}{*}{ p-value } \\
\hline & & & & & & & \\
\hline & \multirow[t]{2}{*}{$\mathbf{N}$} & \multirow[t]{2}{*}{$(\%)$} & \multirow[t]{2}{*}{$\mathbf{N}$} & \multirow[t]{2}{*}{$(\%)$} & \multirow[t]{2}{*}{$\mathbf{N}$} & \multirow[t]{2}{*}{$(\%)$} & \\
\hline & & & & & & & \\
\hline $19-39$ & 1044 & $(10.8)$ & 678 & $(9.0)$ & 366 & $(16.6)$ & $<0.001$ \\
\hline $40-49$ & 2742 & $(28.2)$ & 2006 & $(26.7)$ & 736 & $(33.4)$ & \\
\hline $50-59$ & 3715 & $(38.2)$ & 2969 & (39.5) & 746 & $(33.9)$ & \\
\hline $60-65$ & 2220 & $(22.8)$ & 1865 & $(24.8)$ & 355 & (16.1) & \\
\hline \multicolumn{8}{|l|}{ Estrogen Receptor } \\
\hline Positive & 4205 & $(43.2)$ & 3423 & $(45.5)$ & 782 & $(35.5)$ & $<0.001$ \\
\hline Negative & 2039 & $(21.0)$ & 1433 & (19.1) & 606 & $(27.5)$ & \\
\hline Other \& Unknown & 3477 & $(35.8)$ & 2662 & $(35.4)$ & 815 & $(37.0)$ & \\
\hline \multicolumn{8}{|l|}{ Stage } \\
\hline $0 / \mathrm{I}$ & 3646 & $(37.5)$ & 3054 & $(40.6)$ & 592 & $(26.9)$ & $<0.001$ \\
\hline II & 3304 & $(34.0)$ & 2406 & $(32.0)$ & 898 & $(40.8)$ & \\
\hline III & 690 & $(7.1)$ & 462 & $(6.1)$ & 228 & $(10.3)$ & \\
\hline IV & 360 & $(3.7)$ & 246 & $(3.3)$ & 114 & $(5.2)$ & \\
\hline Unknown & 1721 & $(17.7)$ & 1350 & $(18.0)$ & 371 & $(16.8)$ & \\
\hline \multicolumn{8}{|l|}{ Year of Diagnosis } \\
\hline 1996-1999 & 5608 & $(57.9)$ & 4313 & $(57.5)$ & 1295 & $(59.0)$ & 0.23 \\
\hline 2000-2002 & 4081 & $(42.1)$ & 3181 & $(42.5)$ & 900 & $(41.0)$ & \\
\hline \multicolumn{8}{|l|}{ Surgery } \\
\hline Mastectomy & 5137 & $(52.8)$ & 3924 & $(52.2)$ & 1213 & $(55.1)$ & $<0.001$ \\
\hline Lumpectomy & 3492 & (35.9) & 2786 & (37.1) & 706 & $(32.0)$ & \\
\hline None & 656 & $(6.8)$ & 472 & $(6.2)$ & 184 & $(8.4)$ & \\
\hline Unknown & 436 & $(4.5)$ & 336 & $(4.5)$ & 100 & $(4.5)$ & \\
\hline \multicolumn{8}{|l|}{ Chemotherapy } \\
\hline Yes & 4738 & $(48.7)$ & 3485 & $(46.4)$ & 1253 & $(56.9)$ & $<0.001$ \\
\hline No & 4651 & $(47.8)$ & 3782 & $(50.3)$ & 869 & $(39.5)$ & \\
\hline Unknown & 332 & $(3.5)$ & 251 & $(3.3)$ & 81 & $(3.6)$ & \\
\hline \multicolumn{8}{|l|}{ Radiation Therapy } \\
\hline Yes & 3043 & $(31.3)$ & 2399 & (31.9) & 644 & $(29.2)$ & 0.06 \\
\hline No & 6595 & $(67.8)$ & 5055 & $(67.2)$ & 1540 & $(69.9)$ & \\
\hline Unknown & 83 & $(0.9)$ & 64 & $(0.9)$ & 19 & $(0.9)$ & \\
\hline \multicolumn{8}{|c|}{ Estrogen Receptor POSITIVE } \\
\hline \multicolumn{8}{|l|}{ Hormone therapy } \\
\hline Yes & 1518 & $(36.1)$ & 1265 & $(37.0)$ & 253 & $(32.4)$ & 0.02 \\
\hline No & 2480 & $(59.0)$ & 2000 & $(58.4)$ & 480 & $(61.4)$ & \\
\hline Unknown & 207 & $(4.9)$ & 158 & $(4.6)$ & 49 & $(6.2)$ & \\
\hline \multicolumn{8}{|c|}{ Estrogen Receptor NEGATIVE } \\
\hline \multicolumn{8}{|l|}{ Hormone therapy } \\
\hline Yes & 162 & $(8.0)$ & 124 & $(8.7)$ & 38 & $(6.3)$ & 0.15 \\
\hline No & 1852 & $(90.8)$ & 1290 & $(90.0)$ & 562 & $(92.7)$ & \\
\hline Unknown & 25 & $(1.2)$ & 19 & $(1.3)$ & 6 & $(1.0)$ & \\
\hline Urban & & & & & & & \\
\hline Yes & 6756 & $(69.5)$ & 5131 & (68.3) & 1625 & (73.8) & $<0.001$ \\
\hline No & 2869 & $(29.5)$ & 2302 & $(30.6)$ & 567 & $(25.7)$ & \\
\hline Unknown & 96 & $(1.0)$ & 85 & $(1.1)$ & 11 & $(0.5)$ & \\
\hline
\end{tabular}

*: Due to missing data, total $\mathrm{N}$ for each variable may not equal total $\mathrm{N}$ for group. 
Frequencies and percentages of women who received standard of care and addition to standard of care are presented in Table 2. Only two-thirds of all breast cancer cases received standard of care. No differences were found between African Americans and Whites in receipt of standard of care or addition to standard of care (Table 3). Stage at diagnosis and area of residence were statistically significant in both the standard of care and addition to standard of care adjusted models while year of diagnosis was significant only in the standard of care model. Compared to women who had stage I, women with stage II were $18 \%$ less likely to receive standard of care (Adjusted PR: $0.82(0.78,0.87))$ and women who had stage III were $23 \%$ more likely to receive standard of care (Adjusted PR: 1.23 (1.16, 1.29)). Compared to those with stage I, women with stage II were $23 \%$ less likely to receive addition to standard of care (Adjusted PR: 0.77 $(0.68,0.87))$ and those with stage III (Adjusted PR: 1.20 $(1.06,1.35))$ or stage IV (Adjusted PR: 2.29 (2.11, 2.47)) were more likely to receive addition to standard of care. Those living in urban areas were $7 \%$ more likely to receive standard of care compared to those living in rural areas (Adjusted PR: 1.07 (1.01, 1.12)). Women diagnosed during 2000-2002 were 6\% less likely to receive standard of care compared to women diagnosed during 1996-1999 (Adjusted PR: 0.94 (0.90, 0.99)). For receipt of addition to standard of care, area of residence was significant with those in urban areas being $8 \%$ more likely to receive addition to standard of care compared to those in rural areas (Adjusted PR: $1.08(1.01,1.16))$.

Table 4 presents similar findings separately for African Americans and Whites. For both races, women with stage II were less likely to receive standard of care and addition to standard of care compared to women with stage I, and women with stage III or IV were more likely to receive addition to standard of care compared to women with stage I. When separate binary logit models were used for area of residence, stage, and age, no significant differences were found (data not shown).

Table 2. Distribution of women who received standard of care and addition to standard of care for their breast cancer treatment according to selected characteristics.

\begin{tabular}{|c|c|c|c|c|c|c|}
\hline & \multicolumn{2}{|c|}{$\begin{array}{l}\text { Received Standard of Care } \\
\text { (Yes: } N=2781)\end{array}$} & \multirow[b]{2}{*}{ p-value ${ }^{*}$} & \multicolumn{2}{|c|}{$\begin{array}{l}\text { Received Addition to Standard of Care } \\
\text { (Yes: } N=1370)\end{array}$} & \multirow[b]{2}{*}{ p-value* } \\
\hline & $\mathbf{N}$ & Yes $(\%)$ & & $\mathbf{N}$ & Yes $(\%)$ & \\
\hline \multicolumn{7}{|l|}{ Race } \\
\hline White & 2141 & $(62.6)$ & 0.31 & 1035 & $(42.7)$ & 0.51 \\
\hline African American & 640 & $(64.3)$ & & 335 & $(44.0)$ & \\
\hline \multicolumn{7}{|l|}{ Age (years) } \\
\hline $19-39$ & 336 & (67.3) & 0.13 & 138 & $(32.2)$ & 0.05 \\
\hline $40-49$ & 807 & (63.5) & & 394 & $(42.8)$ & \\
\hline $50-59$ & 1025 & (61.7) & & 535 & $(45.4)$ & \\
\hline $60-65$ & 613 & (62.2) & & 303 & $(42.4)$ & \\
\hline \multicolumn{7}{|l|}{ Estrogen Receptor } \\
\hline Positive & 1501 & (56.3) & $<0.001$ & 803 & $(48.6)$ & $<0.001$ \\
\hline Negative & 887 & (74.5) & & 285 & $(29.2)$ & \\
\hline Other & 393 & (70.3) & & 282 & (50.6) & \\
\hline \multicolumn{7}{|l|}{ Stage ${ }^{\dagger}$} \\
\hline $0 / \mathrm{I}$ & 1300 & $(65.6)$ & $<0.001$ & 520 & $(39.0)$ & $<0.001$ \\
\hline II & 968 & (54.0) & & 293 & $(29.9)$ & \\
\hline III & 513 & $(80.0)$ & & 241 & $(47.0)$ & \\
\hline IV & $\mathrm{n} / \mathrm{a}$ & $\mathrm{n} / \mathrm{a}$ & & 316 & (87.8) & \\
\hline \multicolumn{7}{|l|}{ Year of Diagnosis } \\
\hline 1996-1999 & 1262 & $(61.7)$ & 0.10 & 754 & $(42.7)$ & 0.74 \\
\hline 2000-2002 & 1519 & (64.1) & & 615 & $(43.3)$ & \\
\hline \multicolumn{7}{|l|}{ Urban } \\
\hline Yes & 2031 & $(63.8)$ & 0.003 & 768 & $(37.3)$ & 0.71 \\
\hline No & 712 & $(60.0)$ & & 272 & $(37.1)$ & \\
\hline
\end{tabular}

*: Percent "yes" in each level of specific category. $\uparrow$ : Stage IV could not be included in standard of care because all cases with stage IV were considered to be standard of care in computer algorithm. 
Table 3. Prevalence ratios for standard of care and addition to standard of care for breast cancer treatment.

\begin{tabular}{|c|c|c|c|c|}
\hline \multirow[b]{2}{*}{ Variable } & \multicolumn{2}{|c|}{$\begin{array}{c}\text { Standard of Care } \\
(\mathrm{N}=4375)\end{array}$} & \multicolumn{2}{|c|}{$\begin{array}{l}\text { Addition to Standard of Care } \\
\qquad(\mathrm{N}=3146)\end{array}$} \\
\hline & Crude PR* & Adjusted PR (95\% CI) † & Crude $\mathbf{P R}^{*}$ & Adjusted PR $(95 \%$ CI $) \dagger$ \\
\hline \multicolumn{5}{|l|}{ Race } \\
\hline White & 1.00 & 1.00 & 1.00 & 1.00 \\
\hline African American & 1.03 & $1.00(0.95,1.05)$ & 1.03 & $1.00(0.93,1.07)$ \\
\hline \multicolumn{5}{|l|}{ Age group } \\
\hline $19-39$ & 1.00 & 1.00 & 1.00 & 1.00 \\
\hline $40-49$ & 0.94 & $0.97(0.91,1.04)$ & 1.15 & $1.06(0.92,1.21)$ \\
\hline $50-59$ & 0.92 & $0.94(0.88,1.01)$ & 1.22 & $1.02(0.89,1.17)$ \\
\hline $60-65$ & 0.92 & $0.95(0.88,1.02)$ & 1.14 & $1.04(0.90,1.19)$ \\
\hline \multicolumn{5}{|l|}{ Stage } \\
\hline I & 1.00 & 1.00 & 1.00 & 1.00 \\
\hline II & 0.82 & $0.82(0.78,0.87)$ & 0.77 & $0.77(0.68,0.87)$ \\
\hline III & 1.22 & $1.23(1.16,1.29)$ & 1.20 & $1.20(1.06,1.35)$ \\
\hline IV & $\mathrm{n} / \mathrm{a}$ & $\mathrm{n} / \mathrm{a}$ & 2.25 & $2.29(2.11,2,47)$ \\
\hline \multicolumn{5}{|l|}{ Year of diagnosis } \\
\hline 1996-1999 & 1.00 & 1.00 & 1.00 & 1.00 \\
\hline $2000-2002$ & 0.96 & $0.94(0.90,0.99)$ & 1.01 & $0.98(0.92,1.04)$ \\
\hline \multicolumn{5}{|l|}{ Urban } \\
\hline No & 1.00 & 1.00 & 1.00 & 1.00 \\
\hline Yes & 1.06 & $1.07(1.01,1.12)$ & 0.99 & $1.08(1.01,1.16)$ \\
\hline
\end{tabular}

*: PR=Prevalence ratios

$\dagger$ : Prevalence ratios were adjusted for all variables in the table.

Table 4. Race specific prevalence ratios* for standard of care and addition to standard of care.

\begin{tabular}{|c|c|c|c|c|}
\hline \multirow[b]{2}{*}{ Variable } & \multicolumn{2}{|c|}{ Standard of Care $(\mathrm{N}=4375)$} & \multicolumn{2}{|c|}{ Addition to Standard of Care $(\mathrm{N}=3146)$} \\
\hline & $\begin{array}{l}\text { White } \\
(\mathrm{N}=3384)\end{array}$ & $\underset{(\mathrm{N}=991)}{\mathbf{A A \dagger}}$ & $\begin{array}{l}\text { White } \\
(\mathrm{N}=2391)\end{array}$ & $\underset{(\mathrm{N}=755)}{\mathbf{A A} \dagger}$ \\
\hline \multicolumn{5}{|l|}{ Age group } \\
\hline $19-39$ & 1.00 & 1.00 & 1.00 & 1.00 \\
\hline $40-49$ & $1.00(0.92,1.08)$ & $0.99(0.88,1.11)$ & $1.08(0.91,1.28)$ & $1.04(0.87,1.25)$ \\
\hline $50-59$ & $0.96(0.89,1.04)$ & $0.97(0.86,1.09)$ & $1.06(0.90,1.25)$ & $1.03(0.85,1.24)$ \\
\hline $60-65$ & $0.96(0.88,1.05)$ & $0.96(0.85,1.09)$ & $1.05(0.88,1.26)$ & $1.04(0.84,1.27)$ \\
\hline \multicolumn{5}{|l|}{ Stage } \\
\hline I & 1.00 & 1.00 & 1.00 & 1.00 \\
\hline II & $0.80(0.75,0.85)$ & $0.92(0.82,1.04)$ & $0.77(0.68,0.88)$ & $0.92(0.78,1.08)$ \\
\hline III & $1.24(1.17,1.31)$ & $1.24(1.11,1.39)$ & $1.24(1.09,1.41)$ & $1.06(0.90,1.26)$ \\
\hline IV & $\mathrm{n} / \mathrm{a}$ & $\mathrm{n} / \mathrm{a}$ & $2.20(2.02,2.40)$ & $1.73(1.50,2.00)$ \\
\hline \multicolumn{5}{|c|}{ Year of diagnosis } \\
\hline 1996-1999 & 1.00 & 1.00 & 1.00 & 1.00 \\
\hline 2000-2002 & $0.97(0.92,1.02)$ & $0.87(0.79,0.96)$ & $0.98(0.90,1.05)$ & $0.99(0.88,1.11)$ \\
\hline \multicolumn{5}{|l|}{ Urban } \\
\hline No & 1.00 & 1.00 & 1.00 & 1.00 \\
\hline Yes & $1.07(1.01,1.13)$ & $1.05(0.94,1.18)$ & $1.09(1.01,1.19)$ & $1.00(0.88,1.13)$ \\
\hline
\end{tabular}

*: Prevalence ratios were adjusted for all variables in the table.

†: AA=African American

\section{DISCUSSION}

Breast cancer mortality is higher among African Americans than for Whites; though their breast cancer incidence is lower [3]. This study examines whether or not this racial disparity was due to differences in the receipt of NCCN recommended breast cancer treatment. No racial differences were found for standard of care or addition to standard of care overall or by age, stage, and area of residence. African Americans and Whites received comparable recommended treatment even though there were racial differences by type of treatment received. Therefore, the higher mortality rate of African Americans compared to Whites was shown not to be due to treatment practices varying from the NCCN recommendations. However, the current study found that only two-thirds of women in the overall study population received standard of care for their breast cancer. While no racial differences were found, many breast cancer cases are not receiving standard of care according to the NCCN guidelines. This could be due to patients' preferences, which could not be evaluated by the current study. 
Most previous studies have examined only the frequencies of types of breast cancer treatment (surgery, radiation, chemotherapy, hormone therapy) received. Muss et al [12] reported that fewer African Americans with stage II node-positive disease had breast-conserving surgery, but race was no longer a significant factor in surgery or systemic therapy after adjustment for tumor size, co-morbidity, age, and estrogen receptor status. Another study with 65 African American and 186 White cases examined breast cancer treatment among rural women in North Carolina and found no difference in surgery and adjunct therapy between African Americans and Whites [13]. The current study examined the frequencies of types of breast cancer treatment, but also evaluated the receipt of recommended care for each woman depending on her stage at diagnosis, lymph node status, tumor size, age, and estrogen receptor status. The current study had a large number and large proportion of African American cases and found no racial differences in standard and addition to standard of care.

The differences in receipt of chemotherapy have also been examined as a possible explanation for racial disparities in breast cancer mortality. Muss et al [12] found that no statistically racial differences in receipt of chemotherapy in the multivariate analysis [OR $=0.70$ $(0.40,1.20)]$. Similarly, the study by Tropman et al [13] found no racial differences in receipt of adjuvant therapy for breast cancer. However, these studies did not examine whether or not chemotherapy was appropriate and/or recommended.

Two previous studies [10,16] examined racial differences related to recommended breast cancer treatment. In 1999 Breen et al [16] defined minimum expected therapy according to NIH Consensus conference proceedings and reported that $16 \%$ Whites received minimum expected therapy for their stage of breast cancer compared to only 21\% African Americans. Similarly, another study had an expert $\mathrm{NCI}$-appointed committee to define patterns of care and found that African Americans were as much as 6 percentage points less likely to have had treatment with radiation after mastectomy [10]. While both of these findings were statistically significant, a 5-6\% difference is not clinically relevant. Both of these previous studies based their definition of recommended care on stage only. Confirming these previous findings in recommended care, the current study found no racial differences in standard and addition to standard of care, taking into account not only stage but also lymph node status, tumor size, age, and estrogen receptor status as considered by the NCCN when making its recommendations.
Also consistent with previous research, the current study found that African Americans were younger at diagnosis, less likely to be estrogen receptor positive, and had a later stage at diagnosis compared to Whites (Table 1). Also, women in urban areas were slightly more likely to receive standard and addition to standard of care than women in rural areas (Table 2). This finding probably reflects better access to care for women in urban areas as most cancer treatment facilities are located there.

One important and surprising finding was among women with stage II, representing one third of the study population. Women with stage II were less likely to receive standard and addition to standard of care compared to women with stage I; while women with stage III were more likely to receive standard and addition to standard of care compared to women in stage I. This finding was consistent in the overall adjusted models for standard and addition to standard of care as well as the adjusted models by race. The unusual finding for women with stage II not receiving standard of care is primarily due to not receiving radiation therapy when recommended compared to those in stage I (data not shown). This finding was true in all but one subcategory of women, those with tumors $>50 \mathrm{~mm}$. For women with large tumors and stage II disease, Whites with mastectomy were less likely to receive radiation than African Americans (32.3\% vs. $42.9 \%$, respectively). Radiation therapy is primarily for local recurrence of breast cancer and would not be expected to affect survival.

One limitation of the current study is that the ASCR does not have complete information on breast cancer cases that are treated in another state. Another limitation is that the ASCR does not collect information on co-morbidity, which may affect choice of breast cancer treatment. The analyses were restricted to women treated in Alabama and were under the age of 65 years when diagnosed, so the affect of incomplete treatment information and co-morbidity was reduced. Also, patient compliance to treatment and socioeconomic status were not assessed because this information was not available from the ASCR. Another limitation was that $17.7 \%$ of cases $(\mathrm{N}=1721)$ were missing information on stage at diagnosis. Without the stage at diagnosis, the standard of breast cancer treatment could not be determined. However, those with unknown stage tended to be only slightly less likely to have surgery, chemotherapy, radiation, and hormone therapy compared to those with known stage. The current study was also limited in that available insurance data was recorded as the primary payer for treatment. Because hierarchy of how insurance data is 
classified was unknown, insurance could not be used in our analysis.

Completeness of surgery, chemotherapy and radiation data for the ASCR has been examined in a study undertaken by the authors which showed that chemotherapy is accurately reported but there is an underestimation of surgery and radiation [21]. However, the differences were not due to patient characteristics. The completeness of treatment data was not based on race, appeared to occur at random, and should only minimally affect the results of the current study. Finally, while NCCN guidelines do not substitute for careful physician evaluation and comprehensive care of patients, the current study does allow objective study of the standard of care in a large population of breast cancer patients.

A strength is that our study found that African Americans were younger at time of diagnosis of their breast cancer and were diagnosed at a later stage, which is consistent with other studies. The current study has a large proportion of African Americans $(23 \%)$. Further, not only did we examine standard of breast cancer treatment but also the addition to standard of care. The current study used many criteria to classify standard of care compared to previous studies that did not include all relevant information for determination of meeting the standard and to date, no other study has examined the racial differences in addition to standard of breast cancer treatment.

Another reason proposed to explain why African Americans have a higher death rate from their breast cancer is advanced stage of disease at the time of diagnosis. Several previous studies have suggested that the racial disparity in mortality can be explained by African American women being diagnosed at more advanced stages $[22,23]$. The current study found that African American cases were indeed diagnosed at later stages than White cases. We also found among those in stage III, African Americans were more likely to have received standard of care and addition to standard of care compared to Whites. Therefore, meeting or exceeding standard of care of breast cancer treatment does not explain this disparity. In fact, it may be low adherence to the treatment regimen which is limiting survival of African American patients, but this question was out of the scope of our large population-based study, as this data is not provided by the cancer registry.

In conclusion, we found little in the way of racial differences in standard and addition to standard of care for recommended breast cancer treatment in a large population with a high proportion of African Americans. Therefore, other reasons explain the racial disparity in breast cancer treatment mortality. Future studies could examine patient compliance to treatment and time from diagnosis to treatment as possible explanations for the racial disparity in mortality. A second major finding was that only two-thirds of our study population was found to have received standard of care. Differences were found in standard of care and addition to standard of care according to stage at diagnosis and area of residence which bears further exploration.

\section{Acknowledgements}

The study was supported in part by a training grant from the National Cancer Institute (Grant number 5 R25 CA47888-17). We thank Vicki Nelson, Arica White, and XJ Shen for providing the data from the Alabama Statewide Cancer Registry. We also thank Teresa Morrison and Scott Love for their assistance with the SAS coding of the NCCN recommendations.

\section{Conflict of Interests}

The authors have declared that no conflict of interest exists.

\section{REFERENCES}

1. Cardinez C, Cokkinides V, Gansler T et al. Breast Cancer Facts and Figures 2001-2002. Atlanta Georgia: American Cancer Society. 2001

2. Jemal A, Siegal R, Ward E, et al. Cancer Statistics 2008. CA: A Cancer Journal for Clinicians. 2008;58(2): 71-96.

3. Edwards BK, Brown ML, Wingo PA, et al. Annual report to the nation on the status of cancer, 1975-2002, featuring population-based trends in cancer treatment. J Natl Cancer Inst. 2005;97(19):1407-1427.

4. Coleman EA, O'Sullivan P. Racial differences in breast cancer screening among women from 65 to 74 years of age: trends from 1987-1993 and barriers to screening. J Women Aging. 2001;13(3):23-39.

5. Dunmore C, Plummer P, Regan G, Mattingly D, Jackson S, Millikan R. Re: race and differences in breast cancer survival in a managed care population. J Natl Cancer Inst. 2000;92(20):1690-1691.

6. Velanovich V, Yood MU, Bawle U, et al. Racial differences in the presentation and surgical management of breast cancer. Surgery. 1999;125(4):375-379.

7. McWhorter WP, Mayer WJ. Black/white differences in type of initial breast cancer treatment and implications for survival. Am J Public Health. 1987;77(12):1515-1517.

8. Shavers VL, Harlan LC, Stevens JL. Racial/ethnic variation in clinical presentation, treatment, and survival among breast cancer patients under age 35. Cancer. 2003;97(1):134-147.

9. Athas WF, Adams-Cameron M, Hunt WC, Amir-Fazli A, Key $\mathrm{CR}$. Travel distance to radiation therapy and receipt of radiotherapy following breast-conserving surgery. J Natl Cancer Inst. 2000;92(3):269-271.

10. Diehr P, Yergan J, Chu J, et al. Treatment modality and quality differences for black and white breast-cancer patients treated in community hospitals. Med Care. 1989;27(10):942-958.

11. Elledge RM, Clark GM, Chamness GC, Osborne CK. Tumor biologic factors and breast cancer prognosis among white, Hispanic, and black women in the United States. J Natl Cancer Inst. 1994;86(9):705-712. 
12. Muss HB, Hunter CP, Wesley M, et al. Treatment plans for black and white women with stage II node-positive breast cancer. The National Cancer Institute Black/White Cancer Survival Study experience. Cancer. 1992;70(10):2460-2467.

13. Tropman SE, Ricketts TC, Paskett E, Hatzell TA, Cooper MR, Aldrich T. Rural breast cancer treatment: evidence from the Reaching Communities for Cancer Care (REACH) project. Breast Cancer Res Treat. 1999;56(1):59-66.

14. Arnold RE, Frykberg ER, Kilkenny JW 3rd, Bowers GJ, Mierzejewski J. Trends in surgical treatment of breast cancer at an urban teaching hospital: a six-year review. Am Surg. 1998;64(2):107-111.

15. Morris CR, Cohen R, Schlag R, Wright WE. Increasing trends in the use of breast-conserving surgery in California. Am J Public Health. 2000;90(2):281-284.

16. Breen N, Wesley MN, Merrill RM, Johnson K. The relationship of socio-economic status and access to minimum expected therapy among female breast cancer patients in the National Cancer Institute Black-White Cancer Survival Study. Ethn Dis. 1999;9(1):111-125.

17. Joslyn SA. Racial differences in treatment and survival from early-stage breast carcinoma. Cancer. 2002;95(8):1759-1766.

18. Eley JW, Hill HA, Chen VW, et al. Racial differences in survival from breast cancer. Results of the National Cancer Institute Black/White Cancer Survival Study. JAMA. 1994;272(12):947-954.

19. Franzini L, Williams AF, Franklin J, Singletary SE, Theriault RL. Effects of race and socioeconomic status on survival of 1,332 black, Hispanic, and white women with breast cancer. Ann Surg Oncol. 1997;4(2):111-118.

20. Spiegelman D, Hertzmark E. Easy SAS calculations for risk or prevalence ratios and differences. Am J Epidemiol. 2005;162(3):199-200.

21. Worthington J, Funkhouser EM, Waterbor JWW, Falkson C, Cofield S, Fouad M. Accuracy of registry breast cancer treatment data among cases treated in urban hospitals. Journal of Registry Management. 2008; in press.

22. Newman LA, Alfonso AE. Age-related differences in breast cancer stage at diagnosis between black and white patients in an urban community hospital. Ann Surg Oncol. 1997;4(8):655-662.

23. Moormeier J. Breast cancer in black women. Ann Intern Med. 1996;124(10):897-905. 